Article

\title{
Comparative Study Between Aluminum Monolith and Foam as Carriers for The Intensification of The CO Water Gas Shift Process
}

\author{
Vincenzo Palma, Domenico Pisano and Marco Martino * D \\ Department of Industrial Engineering, University of Salerno, Via Giovanni Paolo II 132, \\ 84084 Fisciano (SA), Italy; vpalma@unisa.it (V.P.); nico.pisano12@gmail.com (D.P.) \\ * Correspondence: mamartino@unisa.it; Tel.: +39-089-964-027
}

Received: 29 September 2018; Accepted: 18 October 2018; Published: 24 October 2018

check for updates

\begin{abstract}
A comparison between the effect of different highly thermal conductive carriers on the performance of $\mathrm{Pt} / \mathrm{CeO}_{2} / \mathrm{Al}_{2} \mathrm{O}_{3}$-based structured catalysts in a water-gas shift reaction, was reported. The structured catalysts were prepared by means of washcoating two carriers, a flow through aluminum monolith and an open cell aluminum foam, with the same contact surface and the same chemical composition of the washcoat. The experiments were carried out under stressful conditions (no dilution and high space velocity), so as to minimize the thermal dispersions and to highlight the effect of the thermal conductivity of the carriers and the material transport phenomena. Both of the catalysts showed a substantially flat thermal profile, while the carbon monoxide conversion was higher with the foam-based catalyst, as a result of the higher temperatures reached. The experimental results were validated with a computational fluid dynamics (CFD) simulation by using the finite elements software, COMSOL Multiphysics ${ }^{\circledR}$. Through the simulation results, it was also possible to investigate the effects of transport phenomena on the two catalytic systems, such as mass and heat transfer.
\end{abstract}

Keywords: water gas shift; process intensification; aluminum foam; aluminum monolith; structured catalyst; thermal conductivity

\section{Introduction}

The water-gas shift process (WGS) plays a crucial role in modulating the $\mathrm{H}_{2} / \mathrm{CO}$ ratio in the syngas [1]; moreover, it can be considered as the first purification step of the reformate gas to produce pure hydrogen, reducing the percentage of carbon monoxide. Unfortunately, the WGS process is not sufficient to meet the $\mathrm{CO}$ tolerance limits for the use of hydrogen in fuel cells [2], so further purification steps are needed, such as methanation [3,4], preferential oxidation [5,6], or the use of a permselective membranes [7-9].

$$
\mathrm{CO}+\mathrm{H}_{2} \mathrm{O} \leftrightarrows \mathrm{H}_{2}+\mathrm{CO}_{2} \quad \Delta \mathrm{H}^{0}{ }_{298}=-41.17 \mathrm{~kJ} / \mathrm{mol}
$$

WGS is a reversible exothermic reaction (1); therefore, it is thermodynamically favored at a low temperature. Under adiabatic conditions, the heat of the reaction causes a thermal gradient on the catalytic bed, which depresses the kinetics at the inlet of the bed, where the temperature is lower, disadvantaging the CO conversion at the outlet of the bed, where the temperature is higher. To overcome these limitations, the WGS process is normally performed in two steps, with an intermediate cooling; in the high temperature shift (HTS) [10] more than $90 \%$ of the CO is quickly converted [11], exploiting the high reaction rates, while in the low temperature shift (LTS), it is possible to reach more than $99 \%$ of CO conversion [12], exploiting the favorable thermodynamic equilibrium. The multi-stage approach has several disadvantages, namely: the intermediate cooling 
step implies a considerable energy expenditure; moreover, the use of two different catalytic systems implies the presence of two different reactors, which can be considered as two separate processes, multiplying the costs. Furthermore, the dimensions of a multi-stage process plant are not suitable for the small-scale applications used in distributed hydrogen production. With the aim of achieving an intensification [13] of the WGS process, our group focused our attention on the use of the structured catalysts obtained by washcoating open cell aluminum foams with noble metal-based formulations [14,15]. Structured catalysts are nowadays used in many applications [16], both in the automotive exhaust gas treatment and in catalytic applications [17,18], where the monolithic and foam reactors have shown many advantages compared with the packed bed [19], such as low pressure drops [20], much more efficient heat and mass transfer [21,22], and a good mechanical stability [23]. The use of high thermal conductivity carriers in the WGS process, allows for realizing the redistribution of the heat of the reaction on the catalytic bed, lowering the outlet temperature, with a corresponding increase in the inlet temperature [24], obtaining benefits in both the reaction kinetics and in the CO conversion [25]. In previous works, the use of heat-conducting composite plates maximized the CO conversion in the tubular reactors for the WGS process [26]. Recently, van DijK at al. proposed the idea of the "isothermal adiabatic reactor", obtained by dissipating the heat throughout the catalytic bed by thermal conduction [27], laying the groundwork for the development of the single stage heat integrated WGS reactor. This strategy is theoretically applicable to all of the exothermic reactions performed with a multi-stage process [28], allowing for a reduction in the steps and the energy requirements of the process. Moreover, the improved heat transfer allows for preventing undesired phenomena, such as thermal hot-spots and runaway reactions, realizing a safer control of the catalytic reactors. Traditionally used catalytic formulations seems to be unsuitable for the preparation of structured catalysts- the HTS catalysts are active only at high temperatures and present waste toxicity problems [29]. However, LTS catalysts are only active in a reduced range of temperatures and present serious problems of pyroforicity [30]. On the other hand, noble metal-based formulations seems to be the best alternative [31]; good results have been obtained with the use of platinum supported on reducible oxides such as ceria $[32,33]$. Furthermore, the use of highly active catalytic formulations at intermediate temperatures allows for hypothesizing their use in a single stage process [34]. In our previous works, we showed that a foam reactor for the WGS process is actually feasible [35], where the heat redistribution along the catalytic bed corresponds to a gain in terms of the CO conversion. Furthermore, we also showed that the performance of the structured catalysts strongly depends on the textural characteristics of the foam carriers [36]. In this paper, we report our results on a comparative study on the use of aluminum foams and monoliths washcoated with a platinum/ceria/alumina based formulation, as a reactor system for the intensification of the WGS reaction. Moreover, we show the results of a CFD modeling of the two systems, based on the finite elements method, in order to investigate the main differences between the two structured catalysts in terms of heat and mass transfer, in the solid carriers and in the gas phase, respectively, as well as to support the experimental results.

\section{Results and Discussion}

\subsection{Characterization Results}

The Brunauer-Emmett-Teller (B.E.T.) specific surface area (s.s.a.) measurements showed the high surface area of the powder washcoat $(\mathrm{W})$ used in the preparation of the structured catalysts, confirming the high stability towards the repeated cycles of calcination and the loading of the active components (Table 1). As previously stressed [25], the particle size distribution of the $\gamma$-alumina, used in the washcoat preparation, is a crucial aspect in order to obtain a good washcoat slurry [37]. Using the optical microscopy analysis, we verified that the most of the alumina particle size did not exceeded $5 \mu \mathrm{m}$. 
Table 1. The $\mathrm{H}_{2}$ uptake in the temperature programmed reduction (TPR) experiments, chemical composition, and specific surface area.

\begin{tabular}{|c|c|c|c|}
\hline Sample & $\mathrm{H}_{2}$ Uptake (mmol/g) & Chemical Composition (wt \%) & SSAB.E.T. $\left(\mathrm{m}^{2} / \mathrm{g}\right)$ \\
\hline Washcoat powder (W) & - & $\gamma-\mathrm{Al}_{2} \mathrm{O}_{3}(100)$ & 186 \\
\hline Ceria/washcoat (CeW) & - & $\gamma-\mathrm{Al}_{2} \mathrm{O}_{3}(73)-\mathrm{CeO}_{2}(27)$ & 138 \\
\hline $\begin{array}{c}\text { Pt/ceria/washcoat } \\
\text { (PtCeW) }\end{array}$ & - & $\gamma-\mathrm{Al}_{2} \mathrm{O}_{3}(73) \mathrm{CeO}_{2}(26)-\mathrm{Pt}(1)$ & 132 \\
\hline $\begin{array}{l}\text { Pt/ceria/washcoat/foam } \\
\text { 10_10/12 (PtCeWF10) }\end{array}$ & 1.01 & - & - \\
\hline $\begin{array}{l}\text { Pt/ceria/washcoat/monolith } \\
\text { (PtCeWM) }\end{array}$ & 1.06 & - & - \\
\hline
\end{tabular}

In order to evaluate the resistance of the coating to mechanical stress [38], we reported the results of the ultrasound adherence test, which showed an excellent resistance both the foam and the monolith (Figure 1). The weight losses were calculated with respect to the weight of the washcoat, and were in the order of $1-2 \%$. Moreover, the losses occurred in the first $15 \mathrm{~min}$, showing an excellent adhesion [39].

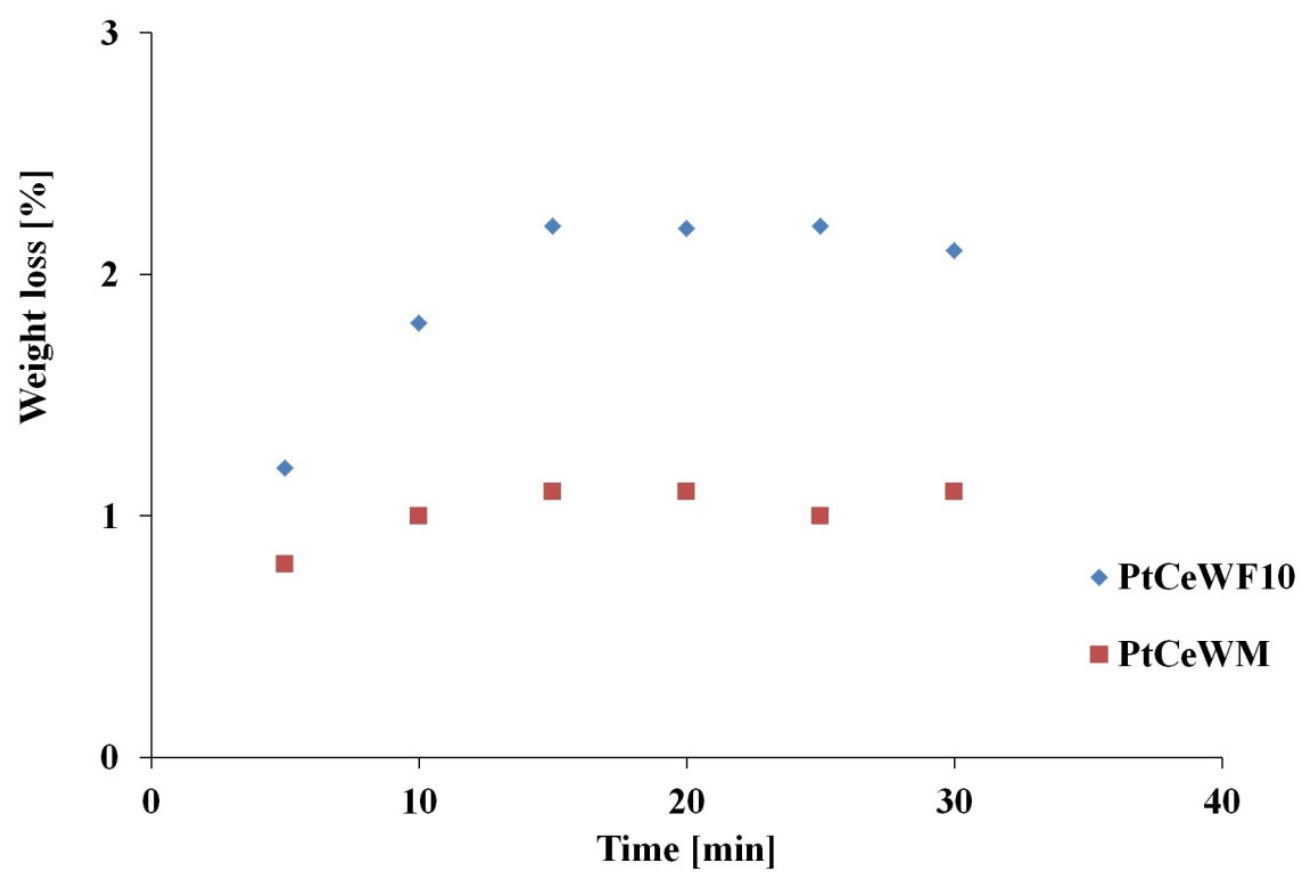

Figure 1. Washcoat weight losses during the ultrasonic adherence tests. PtCeWF10—Pt/ceria/ washcoat/foam 10_10/12; PtCeWM-Pt/ceria/washcoat/monolith.

The XRD patterns of the washcoat allowed for confirming the transformation of pseudoboehmite in $\gamma$-alumina, after the calcination of the powder washcoat at $723 \mathrm{~K}$ [40]. In fact, the diagnostic peak at $2 \theta 28.2$ of pseudoboehmite disappeared in the diffractogram of the powder washcoat [41]. Moreover, the diffractogram of the catalytic formulation $(\mathrm{PtCeW})$ allowed for checking the transformation of cerium nitrate in ceria, with the appearance of the characteristic cubic fluorite structure [42]. While, on the contrary, no peaks attributable to the platinum species were detected, probably due to the low loading (Figure 2). 


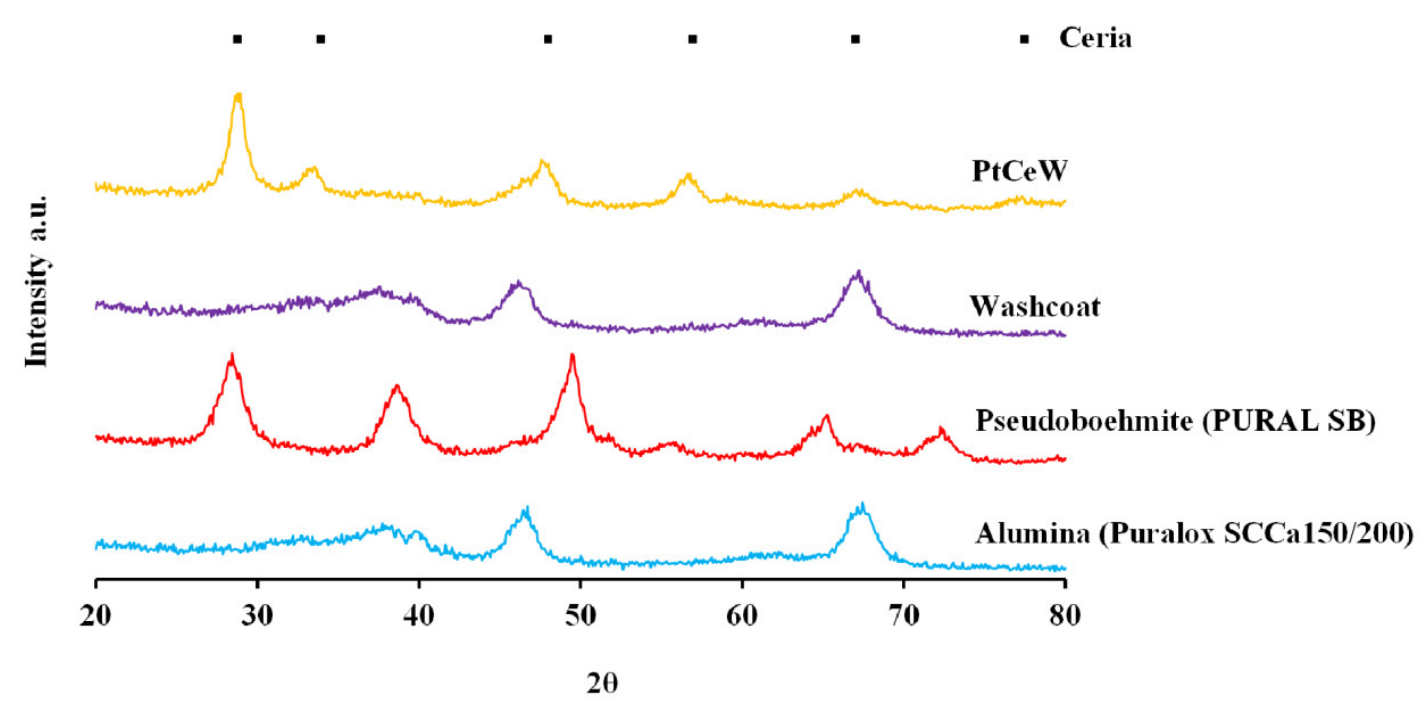

Figure 2. Diffractograms of power materials used in the preparation of the catalysts.

The crystallite sizes, calculated by the Scherrer equation $(\mathrm{k}=0.9)$, were in the order of $5-8 \mathrm{~nm}$, both for ceria and alumina. These values provided a reasonable assurance on the high dispersion of the active components (Table 2) [43].

Table 2. Crystallite sizes.

\begin{tabular}{cccc}
\hline Species & Sample & Peak & Crystallite Size (nm) \\
\hline Ceria & PtCeW & 111 & 7.5 \\
$\gamma$-alumina & - & 440 & 4.8 \\
Platinum & - & - & Not determined \\
\hline
\end{tabular}

The presence of platinum was confirmed by the ED-XRF and Raman analyses.

The $\mathrm{H}_{2}$-TPR experiments were performed immediately before the activity tests, both to evaluate the reducibility of the catalysts and to reduce the platinum oxide species. The TPR profiles of the two structured catalysts showed a similar pattern, with the occurrence of two main broad peaks-the first one, located in the 350-550 K temperature range, was attributed to the PtOx species and surface ceria reduction, while the second one, located in the 550-680 K temperature range, was attributed to the reduction of the bulk ceria [44]. The evaluation of the hydrogen uptake confirmed the occurrence of the spillover effect (Table 1) [45].

\subsection{Activity Tests}

The preliminary screening of the catalytic activity, in order to evaluate the steady state $\mathrm{CO}$ conversions at a high contact time as a function of temperature (Figure 3), showed no significance difference for the two catalysts; these results were related to the catalytic formulation, so no effect of the carrier was detected. The two catalysts approached the thermodynamic equilibrium above $533 \mathrm{~K}$, showing a CO conversion of $50 \%$ at $493 \mathrm{~K}$. 


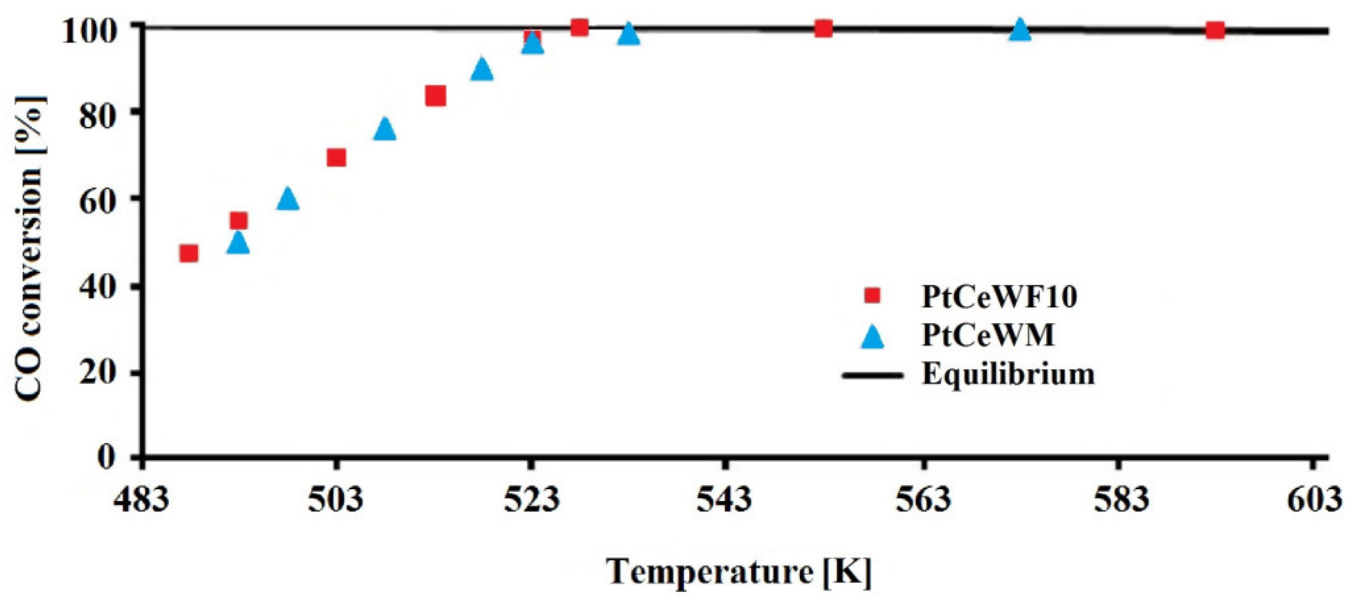

Figure 3. Evaluation of the activity of the two structured catalysts at WHSV $=1.2 \mathrm{gCO} / \mathrm{g}_{\text {cat }} / \mathrm{h}^{-1}$ (contact time $\tau \mathrm{c}=360 \mathrm{~ms}$ ).

In order to highlight the effect of the carrier, a series of activity tests in more stressful conditions were performed, in particular, at a weight hourly space velocity (WHSV) of $10.32 \mathrm{~g}_{\mathrm{CO}} / \mathrm{g}_{\mathrm{cat}} / \mathrm{h}^{-1}$ (contact time $\tau c=107 \mathrm{~ms}$ ), without nitrogen dilution. The operative conditions (i.e., the absence of diluition, the high space velocity, and the reactor design) were chosen with the intent to minimize the thermal dispersions. The use of a thermoexpanding pad between the catalyst and the reactor wall allowed for isolating the bed from the reactor wall, and also allowed for avoiding the by-pass phenomena.

The experiments were carried out in two steps, as follows: In the first (by-pass), the system was brought to the thermal equilibrium by feeding a mixture of vaporized water and nitrogen, by keeping on the catalytic bed a temperature of $533 \mathrm{~K}$. For step two (reaction), the nitrogen was replaced by carbon monoxide, without changing the total flow rate. The temperatures on the catalytic bed were measured with several thermocouples, positioned at the center of the bed along the axial direction (Figure 4), while a sampling of the stream composition was made at an axial position of $\mathrm{z} / \mathrm{L} \approx 0.1$ (by considering the catalyst length equal to L), by means of a stainless-steel capillary connected to a mass spectrometer.

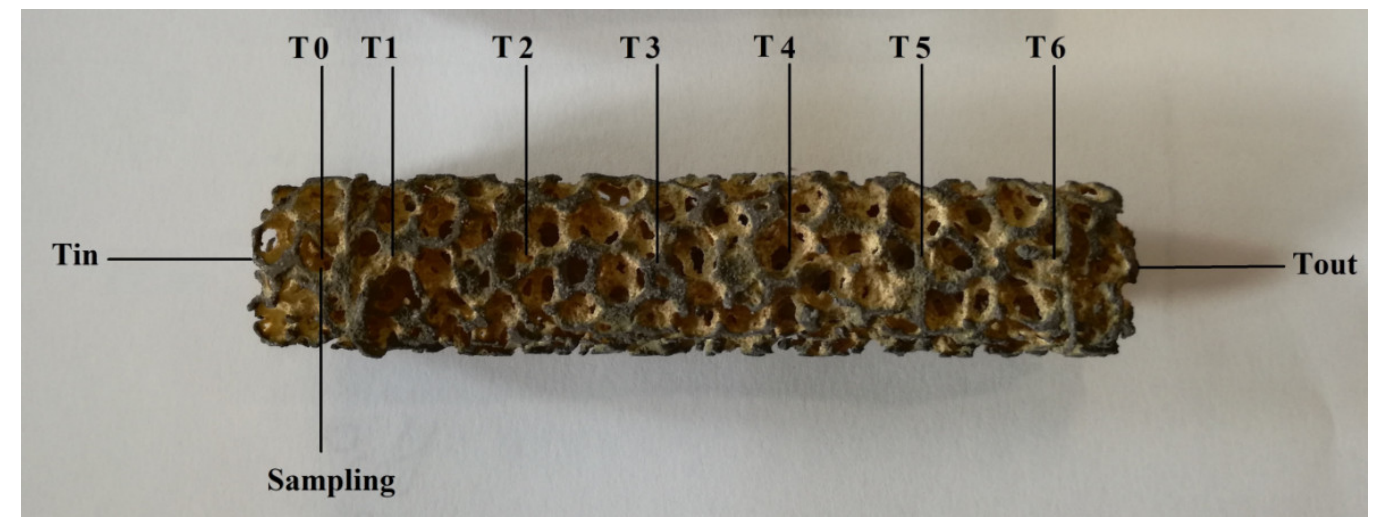

Figure 4. Schematic representation of the sampling of the temperatures over the catalytic bed.

The temperature profile was continuously monitored using a "Multicon system Simex", linked by means of an Ethernet cable to a calculator, and the signals were processed by a Labview interface. Focusing attention on the temperatures at the nearly inlet and at the nearly outlet of the catalytic bed, switching from the by-pass to the reaction induced a rapid increase in the inlet temperature, followed by a similar behavior of the outlet temperature, due to the heat of the reaction. Then, both of the temperatures approached a new thermal equilibrium (Figure 5). The same experiment was performed both with the monolith-based catalyst (PtCeWM) and the foam-based catalyst (PtCeWF10), 
and the results were compared in terms of thermal profile of the bed (Figure 6) and the CO conversion. (Figure 7A). The experimental results were also compared to the simulation ones (Figure 7B).

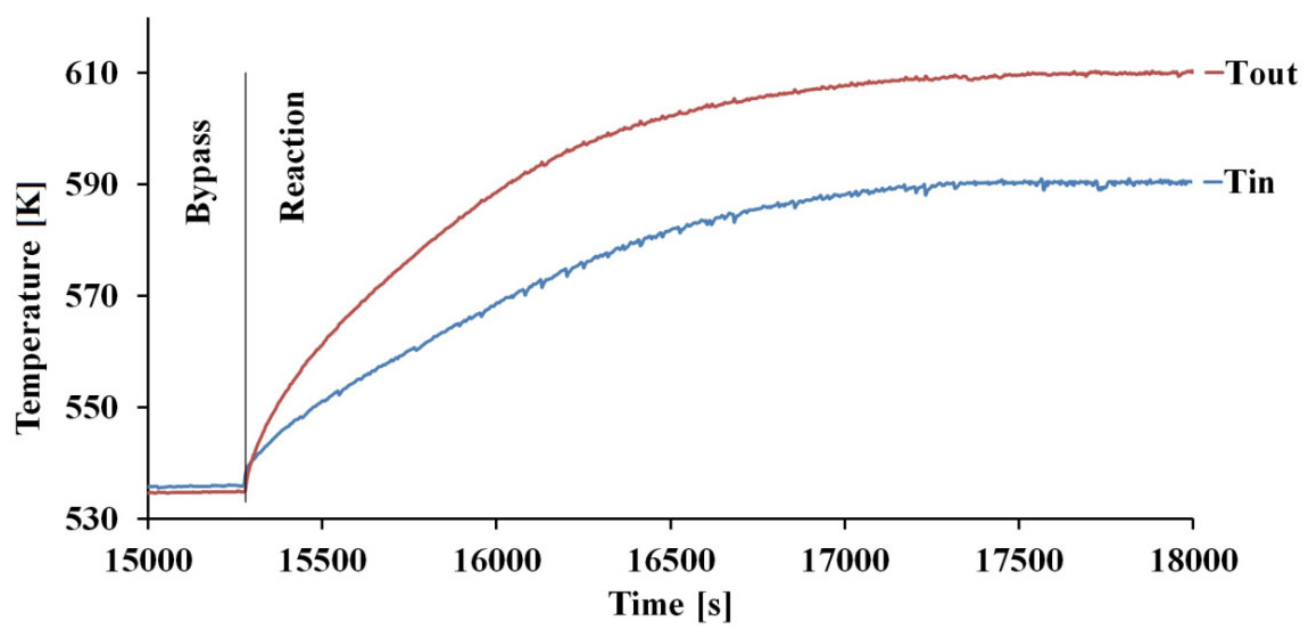

Figure 5. Evolution of the temperature profiles at the inlet and at the outlet of the catalytic bed during the experiment with PtCeWF10.

In Figure 6, it can be observed that both of the samples showed a more pronounced increase of the temperature in the first zone of the catalytic bed (up to $\mathrm{z} / \mathrm{L}=0.2$ ) and reached the temperature of about $583 \mathrm{~K}$ and about $603 \mathrm{~K}$ for PtCeWM and PtCeWF10, respectively. From z/L $=0.2$ on, two different behaviors can be observed-PtCeWM showed an approximate isothermal profile, and PtCeWF10 showed a further increase in temperature, up to a value of about $613 \mathrm{~K}$, followed by a slight decrease up to the end of the catalytic bed.

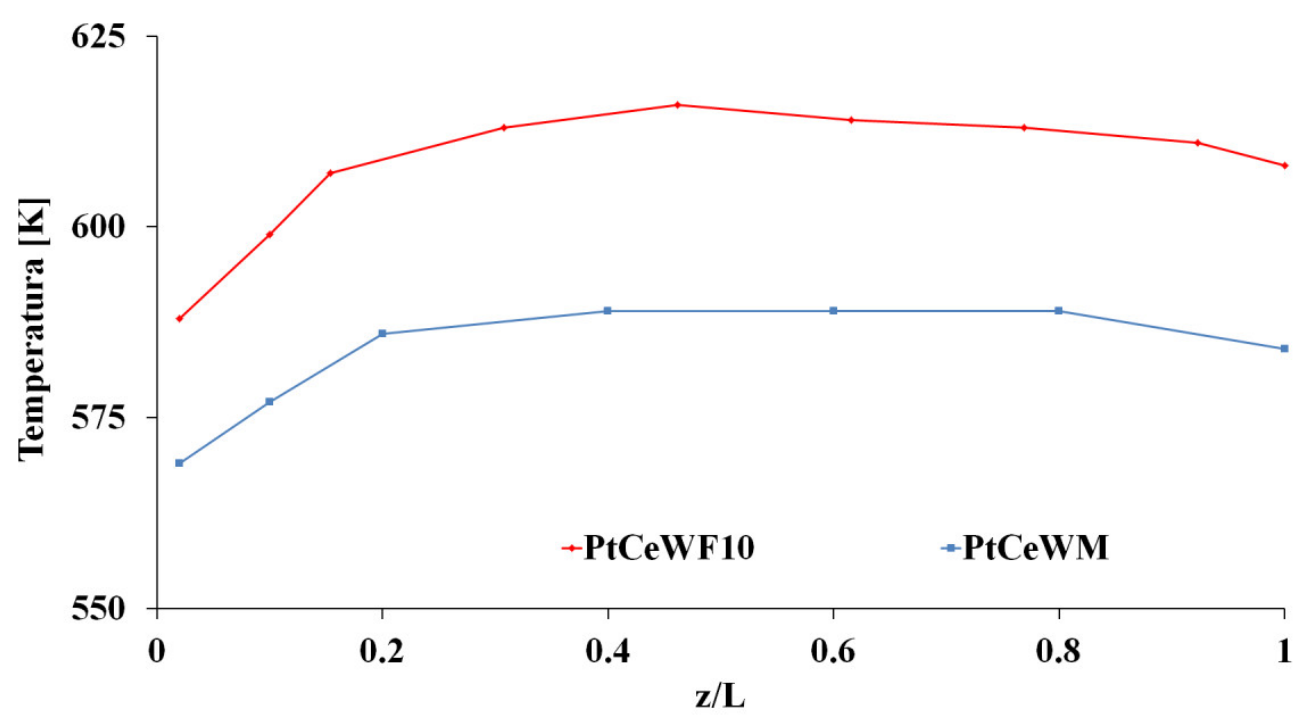

Figure 6. Comparison between the temperature profiles on the catalytic bed at the thermal equilibrium of PtCeWF10 and PtCeWM.

Additionally, Figure 7A shows two different patterns concerning the evolution of $\mathrm{CO}$ conversion versus temperature. Particularly, both of the catalytic systems showed two main zones, as already discussed for the temperature profile along the catalytic bed, as follows: in the first zone, the temperature increased rapidly causing only a little increase in the CO conversion (PtCeWM showed $577 \mathrm{~K}$ and $15 \%$ of CO conversion, while PtCeWF10 showed $599 \mathrm{~K}$ and $28 \%$ of CO conversion); in the second zone, there was a slight increase in the temperature values, together with a marked increase in 
the CO conversion. Therefore, by considering that the second zone covered almost the $90 \%$ of the total length of the catalytic bed, it can be seen that the PtCeWM and PtCeWF10 structured systems allowed for better exploiting the catalyst bed, compared to a more classic packed bed, because the majority of the catalyst works at the higher temperatures, guaranteeing the higher kinetics for the system and avoiding the making of hot-spots [46], which are typical of these kind of reaction systems [47].

A

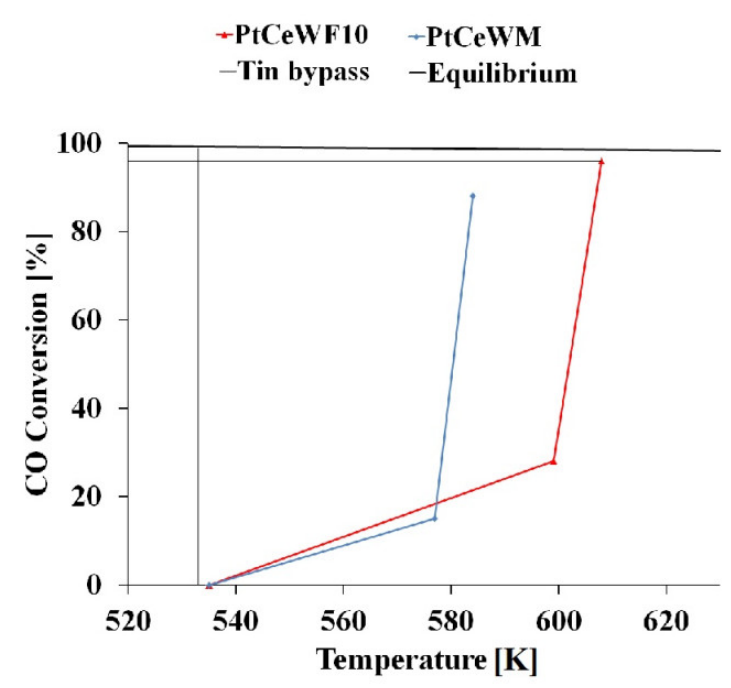

B

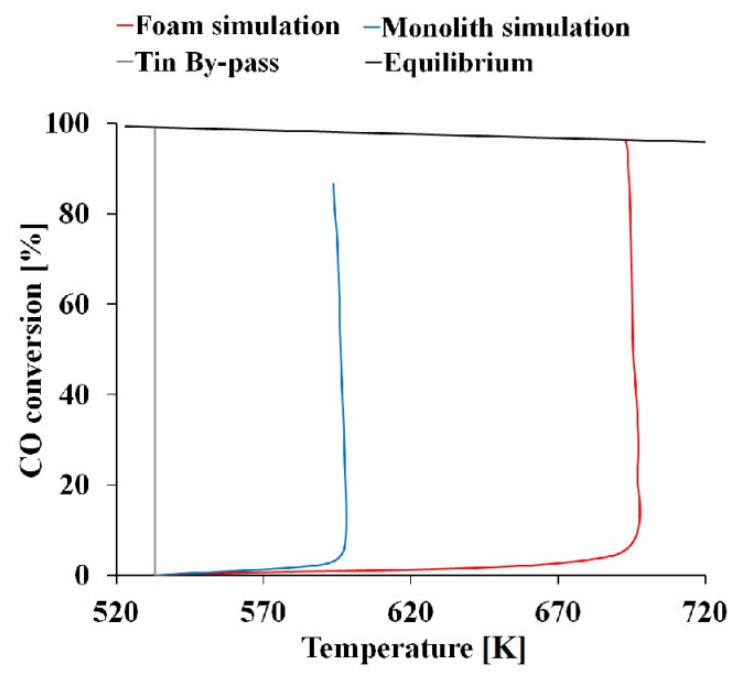

Figure 7. CO conversion versus temperature profile: experimental (A) and simulated (B).

The simulations, shown in Figure 7B, confirmed the trend of the experimental results; particularly, both of the systems showed two main reaction zones, namely: a first one, with low kinetics, where a slight increase in the CO conversion and a pronounced increase in the temperature values occurred; and secondly, with fast kinetics, where there was a marked increase in the CO conversion, while the temperature was maintained almost at a constant. If we compare these results to the temperature profiles observed for the two experimental samples, we can state that the low kinetics zone fills less than $10 \%$ of the total length of the structured catalyst, in both of the investigated cases. So, the use of a structured high thermal conductive catalyst in this kind of exothermic reaction allows for the better exploitation of the whole catalytic volume, by keeping the temperature almost constant for the majority of the catalyst - this favors higher conversions, a longer life for the catalyst, and avoids making hot-spots.

By looking at Figure 7, it can be observed that there was a substantial difference, in terms of catalytic performance, between the two structured systems. The foam-based one approached the thermodynamic equilibrium at higher temperatures, while the monolith-based one showed lower the $\mathrm{CO}$ conversion at lower temperatures. These experimental results were confirmed by the simulation. As the two catalytic systems were designed in order to show the same catalytic surface of contact, the meaning of a different performance can depend on the different heat and mass transfers that are developed inside the structured catalysts, both in the solid and fluid phase. These aspects are discussed largely in the next paragraph.

\subsection{Transport Phenomena Aspects}

In order to better understand the reasons for the different performances of the two structured catalytic systems, a deeper investigation on the results of the simulations was made. In particular, the influence of the transport phenomena (like heat and mass transfer) was evaluated.

With regards to heat transfer, the results of the simulation can be observed in Figure 8, which is divided into four parts. The first two parts (A and B) show the surface plots of the axial and radial total heat flux $\left(\mathrm{W} / \mathrm{m}^{2}\right)$ in the foam (A) and monolith (B) systems; the second parts show the surface 
plots of the temperature distribution in the foam (C) and monolith (D) systems. In Figure 8A,B, the top scales report the radial total heat flux values, while the bottom scales show the axial total heat flux values. In particular, in the case of the foam (Figure 8A), as it was not possible to discriminate between the solid and gas phase (the simulation of the foam is obtained by applying mathematical equations, so that the domain was not obtained by the drawing of the real patterns of the struts), the trend inside the entire domain was evaluated. It was observed that there was a negative axial flux in the first zone of the foam, and a positive axial flux in the second zone. Furthermore, the radial flux was positive in the first zone of the foam, and it became lower approaching the end of the structured catalyst.

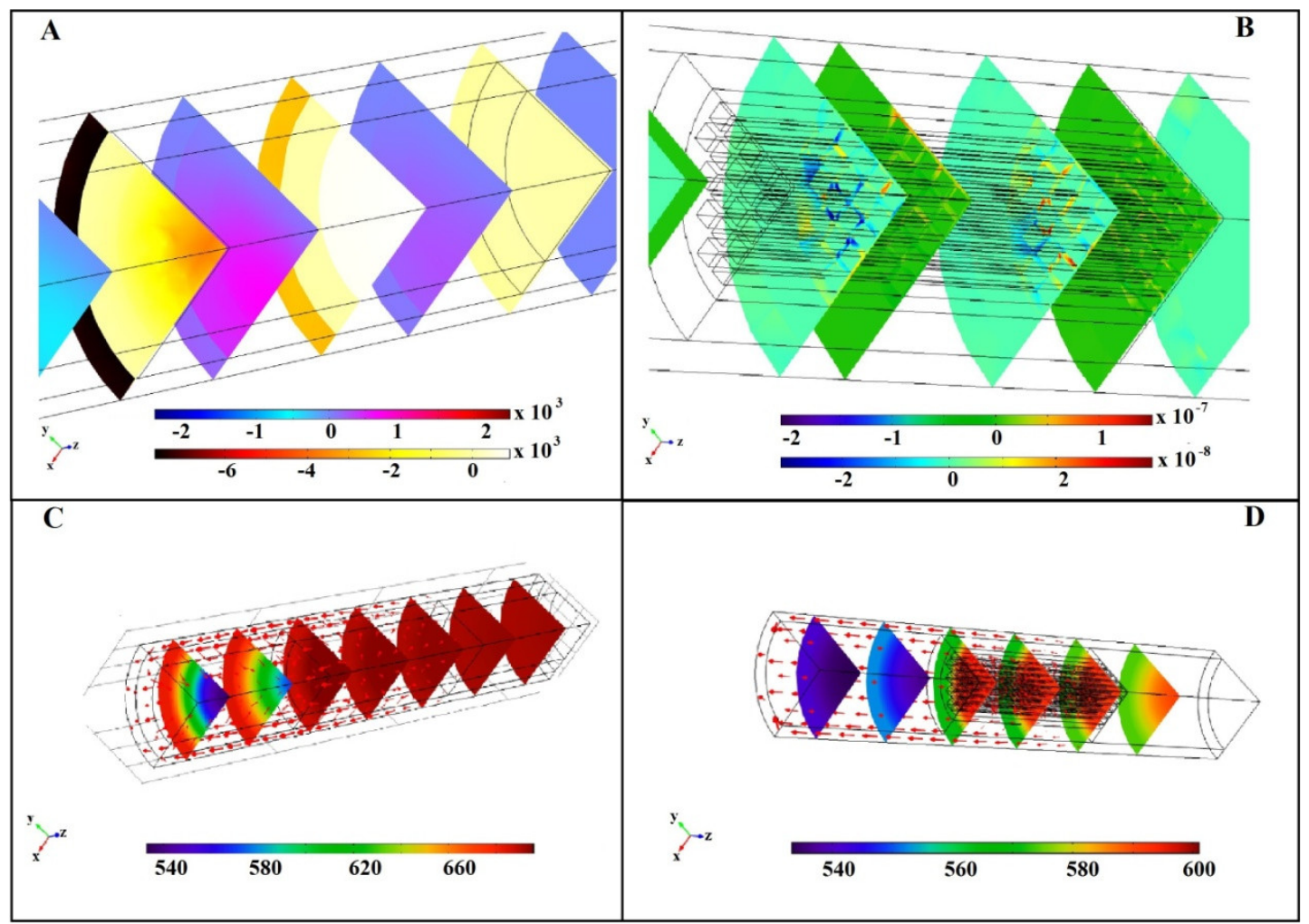

Figure 8. Temperature (K) in the 3D simulation domain: PtCeWF10 (A,C) and PtCeWM (B,D).

On the contrary, by looking at Figure 8B, it can be observed that in the solid phase of the monolith, a negative total axial heat flux predominated in the first part of the structured catalyst, while a positive value was detected for the last part. Regarding the radial heat flux, actually its value in the solid phase, it was almost equal to zero all along the monolith, showing only a slight positive flux near the contact surface with the channels. Instead, in the gas phase, no significant heat flux has been observed, both in the axial and radial direction. This result may be due to the flow field that is developed inside the monolith channels, causing a high resistance at heat exchange at the gas-solid phase interface.

As consequence, the effect of the temperature profiles can be observed in Figure $8 C, D$, which shows two surface plots regarding the temperature distributions in the simulated domains. In particular, regarding the monolith simulation (Figure 8D), there were higher temperatures in the gas phase at the beginning of the catalytic zone compared with the solid phase. As the solid element was not able to develop an efficient heat exchange, because of the high resistance at the solid-gas interface, there is a limitation that causes lower kinetics and disadvantages the $\mathrm{CO}$ conversion. Instead, in the case of the foam (Figure 8C), a higher homogeneity of the temperature can be observed, both in the axial and radial direction; the latter having higher values compared with the monolith. This of course enhanced the kinetics and made the $\mathrm{CO}$ conversion higher, approaching the thermodynamic equilibrium value. The homogeneity of the temperature in the case of the foam is probably due to a lower heat exchange resistance at the solid-gas phase interface, confirmed by the results, in terms of 
the total heat flux obtained in Figure 8A; this, in turn, can depend on the particular geometry can be obtained for the foams, which causes a tortuous flow field that can bring a deep back-mixing. The latter are then able to increase the relative residence time, with respect to a single gas molecule, contributing to enhancing the reaction developing, and so the $\mathrm{CO}$ conversion.

The results of the simulations were investigated also in terms of mass transfer. By looking at Figure 9, where the CO concentration in the 3D domain was presented, in the case of PtCeWF10 (Figure 9A), it can be observed that the CO concentration in the gas phase is function of both axial and radial direction, while PtCeWM (Figure 9B) is only a function of the axial direction. Definitely, the foam-based structured system allowed to reach lower $\mathrm{CO}$ concentration at the outlet of the catalytic bed. So, it can be concluded that, while PtCeWM developed a typical plug flow condition (gaseous phase flows independently in every channels), offering very low back-mixing properties, PtCeWF10 developed a parabolic profile along the radial coordinate, because this system is more affected by the tortuosity given by the struts of the foam, causing a disturbance to the flow field, which actually can induce dispersion both in an axial and radial direction.

$\mathbf{A}$

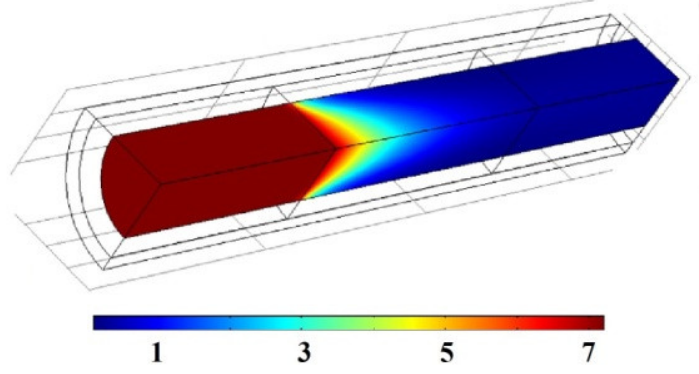

B

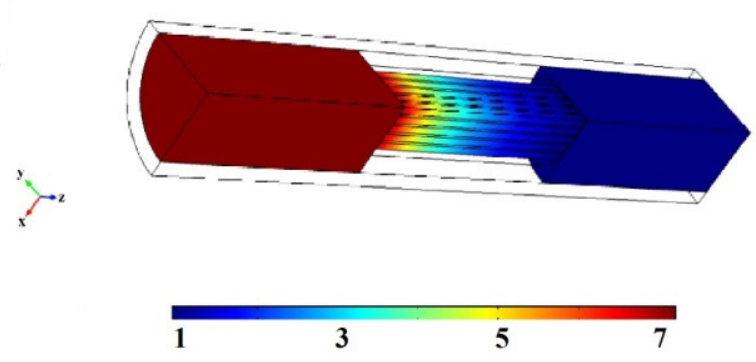

Figure 9. CO concentration $\left(\mathrm{mol} / \mathrm{m}^{3}\right)$ in the 3D simulation domain: PtCeWF10 (A) and PtCeWM (B).

As a consequence of this, PtCeWF10 was able to transfer more heat, generated by the reaction, to the inlet zone, helping increase the temperature, and so making kinetics fast. The advantage given by the more efficient heat transfer in the case of the foam can be also related to the advantage given by the mass flux (the results are shown in Figure 10).

Here, the above scales refer to the radial mass flux, while the scales below refer to the axial mass flux. In particular, it can be observed that for PtCeWF10 (Figure 10A), both the axial and the radial components of the mass flux are almost equal to zero, all along the catalytic bed, showing a complete homogeneity of the system, again caused by the tortuosity of the flow field generated inside the foam. Different behavior can be observed in the case of PtCeWM (Figure 10B), in which the radial component is equal to zero, while the axial component shows a clear gradient, starting from values of about $0.6 \times 10^{-2} \mathrm{~mol} / \mathrm{m}^{2} / \mathrm{s}$ up to zero.
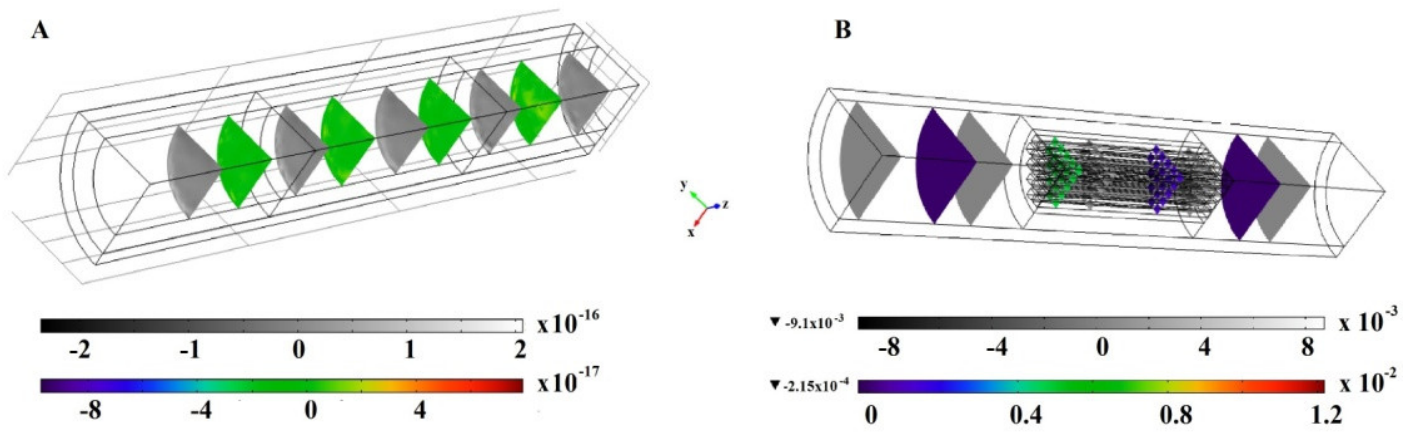

Figure 10. Mass flux $\left(\mathrm{mol} / \mathrm{m}^{2} / \mathrm{s}\right)$ components in the axial direction (colored scale) and radial direction (grey scale), in the 3D simulation domain: PtCeWF10 (A) and PtCeWM (B). 
So, thanks to the irregular and tortuous structure of the foam-based catalyst and the higher void fraction of this carrier compared with the monolith-based one, the well mixed flow and the back-diffusion of the heat transfer in all of the catalytic domains allows for increasing, at the same time, the local residence time, local temperature, and, as consequence of that, the reaction kinetic and CO conversion.

\section{Materials and Methods}

The structured catalysts were prepared in several steps, as follows: the carriers (foam and monolith) were opportunely shaped and degreased, coated with an alumina washcoat, and then impregnated with the salt precursors of the support and the active phase.

\subsection{Carriers Preparation}

The monolith was a cylinder of $5.11 \mathrm{~cm}$ in length, $2.19 \mathrm{~cm}$ in diameter, and $25.86 \mathrm{~g}$ in weight, composed of 76 square channels with a side length of $0.14 \mathrm{~cm}$ and a total surface contact of $217.51 \mathrm{~cm}^{2}$. The foam (10 PPI open cell 10-12\% relative density, ERG Materials and Aerospace, Oakland, CA, USA), was shaped to obtain a cylinder with the same total surface contact compared to the monolith - the length was $6.51 \mathrm{~cm}$, the diameter was $2.19 \mathrm{~cm}$, and the weight $9.34 \mathrm{~g}$. The carriers were degreased by washing with hexane, and were treated with a diluted solution of hydrochloric acid ( $0.1 \mathrm{~N}$ for $20 \mathrm{~min})$ to remove the passivating layer and corrode the surface so as to increase the rugosity, and were then washed with deionized water, dried in an oven (NSV 9000-Bioinstruments, Italy) at $393 \mathrm{~K}$ for $2 \mathrm{~h}$, and calcined at $773 \mathrm{~K}$ for $3 \mathrm{~h}$.

\subsection{Washcoat Preparation}

The washcoat was prepared by suspending the $\gamma$-alumina (PURALOX SCCa 150/200, $\mathrm{d}_{50}=60-150 \mu \mathrm{m}$, Dr. Roberto Clerici, Sasol Performance Chemicals, Italy), previously pulverized by grinding with a Retsch RM100 mill until reaching a particle size distribution of less than $5 \mu \mathrm{m}$ [48], in a colloidal solution, obtained by mixing metilcellulose (viscosity 4'000 cP, Sigma-Aldrich, Milano, Italy) and pseudobohemite (Pural SB, Dr. Roberto Clerici, Sasol Performance Chemicals, Augusta SR, Italy), acidified at $\mathrm{pH}=4$ with nitric acid (65\%, Carlo Erba Reagenti, Cornaredo, Italy). The composition of the final washcoat slurry was $1 \mathrm{wt} \%$ of methylcellulose, $4.6 \mathrm{wt} \%$ of pseudoboehmite, and $15.4 \mathrm{wt} \%$ of $\gamma$-alumina in distilled water.

\subsection{Dip-Coating Procedure}

The washcoating of the carriers was realized by the dip-coating procedure; the carriers were immersed into the washcoat suspension for $20 \mathrm{~min}$, then the excess of the washcoat was removed by centrifuge at $3000 \mathrm{rpm}$ with an CWS 4236 centrifuge (Biotecnica s.a.s., Napoli, Italy). The resulting carrier was dried in an oven at $393 \mathrm{~K}$ for two hours and calcined at $723 \mathrm{~K}$ for $3 \mathrm{~h}$. This procedure was repeated further, until the weight of the loaded alumina reached the desired value of $2.1 \mathrm{~g}$.

\subsection{Catalysts Preparation}

The washcoated carriers were loaded with the desired catalytic formulation; the ceria support was added by impregnation with a solution of cerium (III) nitrate $\left(\mathrm{Ce}\left(\mathrm{NO}_{3}\right)_{3} \times 6 \mathrm{H}_{2} \mathrm{O}, 99.9 \%\right.$-Ce, Strem Chemicals, Bischheim, France), by dipping in the solution for $20 \mathrm{~min}$, and was then dried at $393 \mathrm{~K}$ for two hours and calcined at $723 \mathrm{~K}$ for three hours; this procedure was repeated until the weight of the loaded ceria reached the desired value of $0.75 \mathrm{~g}$. The resulting supports were subsequently loaded with platinum $(\mathrm{Pt})$, following the same procedure, by impregnation with a solution of tetrammineplatinum (II) nitrate $\left(\mathrm{Pt}\left(\mathrm{NH}_{3}\right)_{4}\left(\mathrm{NO}_{3}\right)_{2}, 99 \%\right.$, Strem Chemicals, Bischheim, France) for $20 \mathrm{~min}$, dried at $393 \mathrm{~K}$ for $2 \mathrm{~h}$, and calcined at $723 \mathrm{~K}$ for $3 \mathrm{~h}$, obtaining a Pt loading of $1 \mathrm{wt} \%$ with respect the loaded $\mathrm{CeO}_{2} / \mathrm{Al}_{2} \mathrm{O}_{3}$. For reference and characterization, an aliquot of the washcoat slurry was dried, grinded, and calcined 
at $723 \mathrm{~K}$ for three hours, the resulting powder was impregnated with a cerium (III) nitrate solution and a tetrammineplatinum (II) nitrate solution, dried, and calcined at $723 \mathrm{~K}$ for $3 \mathrm{~h}$ at each step, following the same procedure as was used in the preparation of the structured catalysts.

\subsection{Catalysts Characterization}

The catalysts were fully characterized with several physical-chemical analytical techniques. The B.E.T. specific surface areas were obtained with a Costech Sorptometer 1040 (Costech International, Milan, Italy), by dynamic $\mathrm{N}_{2}$ adsorption measurement at $77 \mathrm{~K}$; the samples were previously treated at $423 \mathrm{~K}$ for $30 \mathrm{~min}$ in a flow of helium. The particle size distributions of the pulverized $\gamma$-alumina were checked by optical microscope analysis (PCVC750K Camera Video, Philips, Amsterdam, Netherlands); a sample of $10 \mathrm{mg}$ was dispersed in $10 \mathrm{~mL}$ of ethylene glycol and sonicated for about $10 \mathrm{~min}$, and then the particle size distribution was evaluated using the microscope. The resistance to the mechanical stress of the washcoted carriers was evaluated using an ultrasound adherence test [49]. The samples were dipped in a beaker containing $100 \mathrm{~mL}$ of petroleum ether (Carlo Erba reagent, Cornaredo, Italy) and the beaker was placed in an ultrasonic bath CP104 (EIA S.p.A., Arezzo, Italy) filled with distilled water. The tests were carried out at $298 \mathrm{~K}$ by applying $60 \%$ of the rated power for six cycles of five minutes. The crystal phases were obtained by X-ray powder diffraction (XRD) with a Brucker D8 Advance (Brucker, Milan, Italy), and the samples were finely grounded and sieved, and then analyzed with a $\mathrm{Cu} \mathrm{K} \alpha$ radiation source $(35 \mathrm{kV} ; 40 \mathrm{~mA})$ in the $2 \theta$ range $20-80^{\circ},(\operatorname{Stp}=737$; Stp size $=0,0814$; $\mathrm{t} / \mathrm{Stp} 0,5 \mathrm{~s})$. The crystallite dimensions were calculated from the diffractograms by applying the Scherrer equation. The chemical composition was checked by means of an ARL ${ }^{\mathrm{TM}}$ QUANT'X ED-XRF spectrometer (Thermo Scientific, Rodano, Italy), while the structural features were evaluated with a Raman spectroscopy using an inVia Raman Microscope (Renishaw, Pianezza, Italy), equipped with a $514 \mathrm{nmAr}$ ion laser operating at $25 \mathrm{~mW}$. The $\mathrm{H}_{2}$-TPR experiments were carried out in the temperature range of $293-723 \mathrm{~K}$, with a reducing stream of $1000 \mathrm{Ncc} / \mathrm{min}$ containing $5 \mathrm{vol} \% \mathrm{of} \mathrm{H}_{2}$ in $\mathrm{N}_{2}$, applying a heating rate of $10 \mathrm{~K} / \mathrm{min}$, in the same reactor used for the activity tests, as described below.

\subsection{Catalytic Activity Tests}

Two different kinds of experiments were carried out in order to evaluate the performance of the catalysts. The structured catalysts were surrounded by a thermo expanding pad with a thickness of $5 \mathrm{~mm}$, and were previously reduced in the $\mathrm{H}_{2}$-TPR experiments. All of the tests were performed at atmospheric pressure in a stainless-steel tubular reactor with an internal diameter of $30 \mathrm{~mm}$ and a length of $40 \mathrm{~cm}$. A preliminary screening was carried out by feeding a reactive mixture composed by $8 \mathrm{vol} \%$ of $\mathrm{CO}, 30 \mathrm{vol} \%$ of $\mathrm{H}_{2} \mathrm{O}$, and $62 \mathrm{vol} \%$ of $\mathrm{N}_{2}$ at a weight hourly space velocity (WHSV) of $1.2 \mathrm{gCO} / \mathrm{g}_{\mathrm{cat}} \mathrm{h}^{-1}$ (contact time $\tau \mathrm{c}=360 \mathrm{~ms}$ ). Furthermore, in order to highlight the effect of the carriers, a set of experiments at high space velocity were carried out, starting from a fixed by-pass temperature of $533 \mathrm{~K}$, by feeding a fully concentrated reactive mixture, composed of $21 \mathrm{vol} \%$ of $\mathrm{CO}$ and $79 \mathrm{vol} \%$ of $\mathrm{H}_{2} \mathrm{O}$, at a weight hourly space velocity (WHSV) of $10.5 \mathrm{gCO} / \mathrm{g}_{\text {cat }} \mathrm{h}^{-1}$ (contact time $\tau \mathrm{c}=107 \mathrm{~ms}$ ). The catalytic performances were evaluated in terms of the $\mathrm{CO}$ conversion $\left.\mathrm{X}_{\mathrm{CO}}\left(\dot{\mathrm{N}}_{\mathrm{CO} \text { in }}-\dot{\mathrm{N}}_{\mathrm{CO} \text { out }}\right) / \dot{\mathrm{N}}_{\mathrm{CO} \text { in }}\right)$, where $\dot{\mathrm{N}}$ represents the molar rate supplied (in) and the molar rate at the outlet of the reactor (out). The CO conversion was evaluated both at the outlet of the reactor and at a position equal to $1 / 10$ of the total catalyst length. Moreover, the temperature was measured along the catalyst length, in order to investigate the evolution of the reaction kinetics by measuring the development of the total heat flux along the catalytic system.

\subsection{Experimental Apparatus}

The experimental plant was assembled with the intent to realize a nearly adiabatic system, minimizing the thermal dispersions. The apparatus can be divided into three main areas, namely: the reagents inlet zone, the furnace, and the products outlet zone. The inlet zone was realized by heating a stainless-steel tube with a $90 \mathrm{~cm}$ length and $6.35 \mathrm{~mm}$ internal diameter, with three resistance operated 
Pid TLK 43 controllers, connected to the stainless-steel reactor, located in a furnace equipped with three independent heating zones, operated with three independent Pid TLK 43 controllers. The presence of two gas supply lines allowed to send, contemporary, gas mixtures both to the reactor and to the analyzer. The outlet zone was realized in the same way as the inlet zone; the reaction products were dried through a refrigerator Julabo F12 and directly sent to an ABB analyzing system equipped with the non-dispersive infrared analyzer Uras 14 for $\mathrm{CO}, \mathrm{CO}_{2}$, and $\mathrm{CH}_{4}$, and the thermal conductivity detector Caldos 17 modules for $\mathrm{H}_{2}$. A further analysis of the gas phase reacting system was made by inserting a stainless-steel capillary at the position of $1 / 10$ of the catalyst length, and the gas stream that was drawn from the system was analyzed by a Hiden Analytical mass spectrometer.

\subsection{CFD Modeling}

CFD modeling was carried out to support the experimental activity, in order to validate the experimental data and to give a further explanation with regards to the transport phenomena linked to the two catalytic systems. The finite elements method software, COMSOL Multiphysics ${ }^{\circledR}$ (Version 5.0, COMSOL S.r.l., Brescia, Italy), was used in this work, and the simulations, both for the monolith-based catalyst and for the foam-based catalyst, were made by considering an ideal adiabatic system.

The two reactor systems were simulated using a 3D model; the z-dimension was chosen as the axial direction, while $\mathrm{x}$ - and $\mathrm{y}$-dimensions were used as the radial directions. The foam-based system was modeled by considering a cylindrical shape catalytic zone, constituted by a porous domain made of aluminum foam in which gas stream flows, and mathematical equations applying for the high porous media flow were used; the reactor system was developed around the catalyst, with the same dimensions as the real experimental system. Moreover, with regards to the monolith-based catalyst, this was modeled by creating a block domain made of aluminum, inside which the channels of the monolith were placed, in which the gaseous stream flowed. Both of the two catalytic systems were modeled by plotting only $\frac{1}{4}$ of the real domain, by considering the complete symmetry of the two systems.

The same operating conditions were applied, as those used for the experimental tests (by-pass temperature equal to $533 \mathrm{~K}$, supplied flow composed by $21 \mathrm{vol} \% \mathrm{CO}$ and $79 \mathrm{vol} \%$ of steam, and WHSV equal $\left.10.32 \mathrm{gCO} / \mathrm{gcat} / \mathrm{h}^{-1}\right)$. An elementary catalyst kinetics that was developed through the experimental data was used (activation energy equal to $68,560 \mathrm{~J} / \mathrm{mol}$ ) [36]. The fluid dynamics of the foam-based system was developed by considering the flow in a porous media, through the application of the Brinkman equation, while the fluid dynamics of the monolith-based system were modeled by considering a free flow in the channels; so, the material and energy balances were solved. The details about the system of the equations used for applying the mass, heat, and momentum balances are provided in a previous paper [24].

The parameters used in the simulations are as follows:

- Total volumetric flow rate: $\mathrm{Q}_{0}=2000 \mathrm{Ncm}^{3} / \mathrm{min}$;

- Volumetric fraction of carbon monoxide: $\mathrm{y}_{\mathrm{COIN}}=0.21$;

- Volumetric fraction of steam water: $\mathrm{y}_{\mathrm{H} 2 \mathrm{OIN}}=0.79$;

- Temperature at the inlet of the reaction system: $\mathrm{T}_{\mathrm{IN}}=533 \mathrm{~K}$;

- Thermal conductivity of bulk aluminum: $\mathrm{k}=171 \mathrm{~W} / \mathrm{m} / \mathrm{K}$;

- Effective thermal conductivity of the solid carriers: calculated as volumetric average;

- Foam carrier void fraction: $\varepsilon=89 \%$;

- Foam carrier permeability: $\mathrm{K}=1 \times 10^{-4} \mathrm{~m}^{2}$;

- Density of the noble metal-based catalyst: $\varrho=600 \mathrm{~kg} / \mathrm{m}^{3}$;

- Standard heat of reaction: $\Delta \mathrm{H}_{\mathrm{R}(298 \mathrm{~K})}=-41.17 \mathrm{~kJ} / \mathrm{mol}$.

The boundary conditions for the present work follows: 
- At $\mathrm{z}=0 \rightarrow \mathrm{U}=\mathrm{U}_{0}$ (average gas velocity) $=\mathrm{Q}_{0} / \mathrm{S}$ where $\mathrm{S}$ is the cross-sectional area;

- At $\mathrm{z}=\mathrm{L} \rightarrow \mathrm{p}=1$ bar (atmospheric pressure).

\section{ENERGY BALANCE}

- At $\mathrm{z}=0 \rightarrow \mathrm{T}=\mathrm{T}_{\mathrm{IN}}$ (temperature at the inlet of the reaction system);

- At $\mathrm{z}=\mathrm{L} \rightarrow-\mathrm{dT} / \mathrm{dz}=0$.

MASS BALANCE

- $\quad$ At $\mathrm{z}=0 \rightarrow \mathrm{yCO}_{\mathrm{CO}}=\mathrm{y}_{\mathrm{CO}}, \mathrm{y}_{\mathrm{H} 2 \mathrm{O}}=\mathrm{y}_{\mathrm{H} 2 \mathrm{OIN}}$;

- At $\mathrm{z}=\mathrm{L} \rightarrow-\mathrm{dC}_{\mathrm{i}} / \mathrm{dz}=0$ where $\mathrm{C}_{\mathrm{i}}=$ molar concentration of the $\mathrm{i}$-species.

The finite elements numerical steady state study was used to solve the differential equations of the multiphysics problem, by using a less refined grid for most of the flow and a fine and boundary layer grid inside the catalytic section and near the wall regions.

\section{Conclusions}

In this work, we showed the results of a comparative study on the WGS reaction, between two structured catalysts, characterized by two different carriers (i.e., aluminum monolith (PtCeWM) and aluminum foam (PtCeWF10)); the reaction system was developed with the aim of reducing the thermal dispersions under stressful operative conditions for the catalyst. The results were validated by making simulations with the use of the finite elements software COMSOL Multiphysics ${ }^{\circledR}$.

The experimental results highlighted three main aspects, as follows: the thermal profile of PtCeWM was flatter than that of PtCeWF10, the temperatures on the PtCeWM bed were lower of about $20 \mathrm{~K}$ than those on PtCeWF10, the CO conversion was higher with PtCeWF10 compared with PtCeWM.

The flatter temperature profile of PtCeWM was explained as the result of the higher effective thermal conductivity of the monolith carrier. The lower conversion of CO, obtained with PtCeWM, was explained as the result of the lower temperatures reached, which consequently caused low kinetics and a lower development of reaction heat.

The simulation results confirmed the trend observed for the experimental results. In order to better understand the meaning of the performance of the two catalytic systems, the simulation results were also analyzed in terms of heat and mass transfer. This study revealed a high resistance of heat exchange at the solid-gas phase interface, regarding the monolith system, due to the flow field developed in its channels. On the contrary, in the foam system, a tortuous flow field developed, which favored both the axial and radial dispersion of heat and mass, generating a more homogeneous distribution of temperature and gas concentration, and giving higher temperatures, faster kinetics, and a higher carbon monoxide conversion. For these reasons, it can be stated that a structured foam-based catalytic system for the WGS reaction could be more efficient than a monolith system, in view of a one stage process.

Author Contributions: Data curation, D.P. and M.M.; formal analysis, M.M.; funding acquisition, V.P.; methodology, V.P. and M.M.; resources, V.P.; supervision, V.P.; validation, D.P.; writing—original draft, D.P.; writing-review and editing, M.M.

Funding: This work has received funding from the European Union's Horizon 2020 research and innovation programme, under the Marie Skłodowska-Curie grant agreement (No. 734561).

Acknowledgments: The authors wish to thankfully acknowledge Domenico Matera for his valuable contribution to the experimental activity.

Conflicts of Interest: The authors declare no conflicts of interest. 


\section{References}

1. Bukur, D.B.; Todic, B.; Elbashir, N. Role of water-gas-shift reaction in Fischer-Tropsch synthesis on iron catalysts: a review. Catal. Today 2016, 275, 66-75. [CrossRef]

2. Baschuk, J.J.; Li, X. Carbon monoxide poisoning of proton exchange membrane fuel cells. Int. J. Energy Res. 2001, 25, 695-713. [CrossRef]

3. Zyryanova, M.M.; Snytnikov, P.V.; Amosov, Y.I.; Ven'yaminov, S.A.; Golosman, E.Z.; Sobyanin, V.A. Selective methanation of $\mathrm{CO}$ in the presence of $\mathrm{CO}_{2}$ in hydrogen-containing mixtures on nickel catalysts. Kinet. Catal. 2010, 51, 907-913. [CrossRef]

4. Zhang, M.; Yu, F.; Li, J.; Chen, K.; Yao, Y.; Li, P.; Zhu, M.; Shi, Y.; Wang, Q.; Guo, X. High CO Methanation Performance of Two-Dimensional Ni/MgAl Layered Double Oxide with Enhanced Oxygen Vacancies via Flash Nanoprecipitation. Catalysts 2018, 8, 363. [CrossRef]

5. Wootsch, A.; Descorme, C.; Duprez, D. Preferential oxidation of carbon monoxide in the presence of hydrogen (PROX) over ceria-zirconia and alumina-supported Pt catalysts. J. Catal. 2004, 225, 259-266. [CrossRef]

6. Fiorenza, R.; Spitaleri, L.; Gulino, A.; Scirè, S. Ru-Pd Bimetallic Catalysts Supported on $\mathrm{CeO}_{2}-\mathrm{MnO}$ Xxides as Efficient Systems for $\mathrm{H}_{2}$ Purification through CO Preferential Oxidation. Catalysts 2018, 8, 203. [CrossRef]

7. Fernandez, E.; Helmi, A.; Coenen, K.; Melendez, J.; Viviente, J.L.; Pacheco Tanaka, D.A.; Van Sint Annaland, M.; Gallucci, F. Development of thin Pd-Ag supported membranes for fluidized bed membrane reactors including WGS related gases. Int. J. Hydrogen Energy 2015, 40, 3506-3519. [CrossRef]

8. Tocci, E.; Pullumbi, P. Molecular simulation of realistic membrane models of alkylated PEEK membranes. Mol. Simul. 2006, 32, 145-154. [CrossRef]

9. Ghasemzadeh, K.; Aghaeinejad-Meybodi, A.; Basile, A. Hydrogen production as a green fuel in silica membrane reactor: Experimental analysis and artificial neural network modeling. Fuel 2018, 222, 114-124. [CrossRef]

10. Hallac, B.B.; Brown, J.C.; Stavitski, E.; Harrison, R.G.; Argyle, M.D. In Situ UV-Visible Assessment of Iron-Based High-Temperature Water-Gas Shift Catalysts Promoted with Lanthana: An Extent of Reduction Study. Catalysts 2018, 8, 63. [CrossRef]

11. Kraussler, M.; Binder, M.; Fail, S.; Bosch, K.; Hackel, M.; Hofbauer, H. Performance of a water gas shift pilot plant processing product gas from an industrial scale biomass steam gasification plant. Biomass Bioenergy 2016, 89, 50-57. [CrossRef]

12. Uchida, H.; Isogai, N.; Oba, M.; Hasegawa, T. The Zinc Oxide-Copper Catalyst for Carbon Monoxide-Shift Conversion. I. The Dependency of the Catalytic Activity on the Chemical Composition of the Catalyst. Bull. Chem. Soc. Jpn. 1967, 40, 1981-1986. [CrossRef]

13. Reay, D.; Ramshaw, C.; Harvey, A. Process Intensification, Engineering for Efficiency: Sustainability and Flexibility, 1st ed.; Butterworth-Heinemann: Oxford, UK, 2008.

14. Palma, V.; Pisano, D.; Martino, M.; Ricca, A.; Ciambelli, P. High Thermal Conductivity Structured Carriers for Catalytic Processes Intensification. Chem. Eng. Trans. 2015, 43, 2047-2052. [CrossRef]

15. Palma, V.; Martino, M. Pt-Re Based Catalysts for the Realization of a Single Water Gas Shift Process. Chem. Eng. Trans. 2017, 57, 1657-1662. [CrossRef]

16. Jiang, Y.; Ma, L.; Zhou, L.; Ma, L.; He, Y.; Zhang, X.; Gao, J. Structured interlocked-microcapsules: A novel scaffold for enzyme immobilization. Catal. Commun. 2017, 88, 35-38. [CrossRef]

17. Tomašić, V.; Gomzi, Z. Development of the Structured Catalysts for the Exhaust Gas Treatment. Chem. Biochem. Eng. Q. 2001, 15, 109-115.

18. Tronconi, E.; Groppi, G.; Visconti, C.G. Structured catalysts for non-adiabatic applications. Curr. Opin. Chem. Eng. 2014, 5, 55-67. [CrossRef]

19. Vita, A.; Italiano, C.; Pino, L.; Frontera, P.; Ferraro, M.; Antonucci, V. Activity and stability of powder and monolith-coated Ni/GDC catalysts for $\mathrm{CO}_{2}$ methanation. Appl. Catal. B Environ. 2018, 226, 384-395. [CrossRef]

20. Camacho, Y.S.M.; Bensaid, S.; Lorentzou, S.; Russo, N.; Fino, D. Structured catalytic reactor for soot abatement in a reducing atmosphere. Fuel Process. Technol. 2017, 167, 462-473. [CrossRef]

21. Brautsch, A.; Griffin, T.; Schlegel, A. Heat transfer characterization of support structures for catalytic combustion. Int. J. Heat Mass Transfer 2002, 45, 3223-3231. [CrossRef] 
22. Giani, L.; Groppi, G.; Tronconi, E. Mass-Transfer Characterization of Metallic Foams as Supports for Structured Catalysts. Ind. Eng. Chem. Res. 2005, 44, 4993-5002. [CrossRef]

23. Wu, D.; Kong, S.; Zhang, H.; Li, Y. Mechanical stability of monolithic catalysts: Factors affecting washcoat adhesion and cohesion during preparation. Aiche J. 2014, 60, 2765-2773. [CrossRef]

24. Palma, V.; Pisano, D.; Martino, M. CFD modeling of the influence of carrier thermal conductivity for structured catalysts in the WGS reaction. Chem. Eng. Sci. 2018, 178, 1-11. [CrossRef]

25. Palma, V.; Pisano, D.; Martino, M.; Ciambelli, P. Structured catalysts with high thermoconductive properties for the intensification of Water Gas Shift process. Chem. Eng. J. 2016, 304, 544-551. [CrossRef]

26. Baronskaya, N.A.; Khasin, A.A.; Smirnov, E.I.; Yur'eva, T.M. Variants of the organization of a controlledtemperature-profile catalyst bed in a tubular reactor for the single-step water gas shift reaction. Theor. Found. Chem. Eng. 2009, 43, 366-373. [CrossRef]

27. Van Dijk, H.A.J.; Boon, J.; Nyqvist, R.N.; Van Den Brink, R.W. Development of a single stage heat integrated water-gas shift reactor for fuel processing. Chem. Eng. J. 2010, 159, 182-189. [CrossRef]

28. Eigenberger, G. Catalytic fixed-bed reactors. Handb. Heterogen. Catal. 2008, 10, 2075-2106. [CrossRef]

29. Zhu, M.; Wachs, I.E. Iron-Based Catalysts for the High-Temperature Water-Gas Shift (HTWGS) Reaction: A Review. ACS Catal. 2016, 6, 722-732. [CrossRef]

30. Kam, R.; Scott, J.; Amal, R.; Selomulya, C. Pyrophoricity and stability of copper and platinum based water-gas shift catalysts during oxidative shut-down/start-up operation. Chem. Eng. Sci. 2010, 65, 6461-6467. [CrossRef]

31. Song, L.; Lu, Z.; Zhang, Y.; Su, Q.; Li, L. Hydrogen-Etched $\mathrm{TiO}_{2}-\mathrm{x}$ as Efficient Support of Gold Catalysts for Water-Gas Shift Reaction. Catalysts 2018, 8, 26. [CrossRef]

32. Piumetti, M.; Bensaid, S.; Andana, T.; Dosa, M.; Novara, C.; Giorgis, F.; Russo, N.; Fino, D. Nanostructured Ceria-Based Materials: Effect of the Hydrothermal Synthesis Conditions on the Structural Properties and Catalytic Activity. Catalysts 2017, 7, 174. [CrossRef]

33. Santos, J.L.; Bobadilla, L.F.; Centeno, M.A.; Odriozola, J.A. Operando DRIFTS-MS Study of WGS and rWGS Reaction on Biochar-Based Pt Catalysts: The Promotional Effect of Na. J. Carbon Res. 2018, 4, 47. [CrossRef]

34. Jeong, D.-W.; Potdar, H.S.; Shim, J.-O.; Jang, W.-J.; Roh, H.-S. $\mathrm{H}_{2}$ production from a single stage water gas shift reaction over $\mathrm{Pt} / \mathrm{CeO}_{2}, \mathrm{Pt} / \mathrm{ZrO}_{2}$, and $\mathrm{Pt} / \mathrm{Ce}(1 \mathrm{Lx}) \mathrm{Zr}(\mathrm{x}) \mathrm{O}_{2}$ catalysts. Int. J. Hydrogen Energy 2013, 38, 4502-4507. [CrossRef]

35. Palma, V.; Pisano, D.; Martino, M. Structured noble metal-based catalysts for the WGS process intensification. Int. J. Hydrogen Energy 2018, 43, 11745-11754. [CrossRef]

36. Palma, V.; Pisano, D.; Martino, M. The influence of the textural properties of aluminum foams as catalyst carriers for water gas shift process. Int. J. Hydrogen Energy 2017, 42, 23517-23525. [CrossRef]

37. Nijhuis, T.A.; Beers, A.E.W.; Vergunst, T.; Hoek, I.; Kapteijn, F.; Moulijn, J.A. Preparation of monolithic catalysts. Cataly. Rev. Sci. Eng. 2001, 43, 345-380. [CrossRef]

38. Valentini, M.; Groppi, G.; Cristiani, C.; Levi, M.; Tronconi, E.; Forzatti, P. The deposition of $\gamma-\mathrm{Al}_{2} \mathrm{O}_{3}$ layers on ceramic and metallic supports for the preparation of structured catalysts. Catal. Today 2001, 69, 307-314. [CrossRef]

39. Barbero, B.P.; Costa-Almeida, L.; Sanz, O.; Morales, M.R.; Cadus, L.E.; Montes, M. Washcoating of metallic monoliths with a $\mathrm{MnCu}$ catalyst for catalytic combustion of volatile organic compounds. Chem. Eng. J. 2008, 139, 430-435. [CrossRef]

40. Xie, Y.; Kocaefe, D.; Kocaefe, Y.; Cheng, J.; Liu, W. The Effect of Novel Synthetic Methods and Parameters Control on Morphology of Nano-alumina Particles. Nanosc. Res. Lett. 2016, 11, 259-270. [CrossRef] [PubMed]

41. Adamowska, M.; Da Costa, P. Structured Pd $/ \gamma-\mathrm{Al}_{2} \mathrm{O}^{3}$ Prepared by Washcoated Deposition on a Ceramic Honeycomb for Compressed Natural Gas Applications. J. Nanopart. 2015, 2015, 1-9. [CrossRef]

42. Kim, Y.-H.; Kim, S.-K.; Kim, N.; Park, J.-G.; Paik, U. Crystalline structure of ceria particles controlled by the oxygen partial pressure and STI CMP performances. Ultramicroscopy 2008, 108, 1292-1296. [CrossRef] [PubMed]

43. Borodziński, A.; Bonarowska, M. Relation between Crystallite Size and Dispersion on Supported Metal Catalysts. Langmuir 1997, 13, 5613-5620. [CrossRef]

44. Damyanova, S.; Bueno, J.M.C. Effect of $\mathrm{CeO}_{2}$ loading on the surface and catalytic behaviors of $\mathrm{CeO}_{2}-\mathrm{Al}_{2} \mathrm{O}_{3}$-supported Pt catalysts. Appl. Catal. A Gen. 2003, 253, 135-150. [CrossRef] 
45. Dutta, G.; Waghmare, U.V.; Baidya, T.; Hegde, M.S. Hydrogen spillover on $\mathrm{CeO}_{2} / \mathrm{Pt}$ : enhanced storage of active hydrogen. Chem. Mater. 2007, 19, 6430-6436. [CrossRef]

46. Tiana, J.; Lin, J.; Xua, M.; Wan, S.; Lin, J.; Wang, Y. Hexagonal boron nitride catalyst in a fixed-bed reactor for exothermic propane oxidation dehydrogenation. Chem. Eng. Sci. 2018, 186, 142-151. [CrossRef]

47. Salzano, E.; Cammarota, F.; Di Benedetto, A.; Di Sarli, V. Explosion behavior of hydrogenemethane/air mixtures. J. Loss Prev. Process Ind. 2012, 25, 443-447. [CrossRef]

48. Agrafiotis, C.; Tsetsekou, A. The effect of powder characteristics on washcoat quality. Part I: Alumina washcoats. J. Eur. Ceram. Soc. 2000, 20, 815-824. [CrossRef]

49. Yasaki, S.; Yoshino, Y.; Ihara, K.; Ohkubo, K. Method of Manufacturing an Exhaust Gas Purifying Catalyst. U.S. Patent 5,208,206, 4 May 1993.

(c) 2018 by the authors. Licensee MDPI, Basel, Switzerland. This article is an open access article distributed under the terms and conditions of the Creative Commons Attribution (CC BY) license (http:/ / creativecommons.org/licenses/by/4.0/). 